\title{
COVID-19 immune system and exercise
}

\section{COVID-19 immün sistem ve egzersiz ${ }^{1}$}

\author{
Zait Burak Aktuğ ${ }^{2}$ \\ Rüçhan İri ${ }^{3}$ \\ Nazlım Aktuğ Demir ${ }^{4}$
}

\begin{abstract}
COVID-19, which became a current issue as a result of the pneumonia cases with unknown etiology in Wuhan City, Hubei Province of China on December 31, 2019, has started to spread throughout the world and deaths related to it have increased rapidly. Isolation, which is an important step in the control of this disease, has many physiological and psychological effects. Initiating a sudden quarantine situation means a radical change in the lifestyle of the population. Changing lifestyles and behaviours may result in insufficient levels of physical activity and inadequate movement, which increases the risk of developing conditions such as diabetes, hypertension, cardiovascular diseases and respiratory diseases. During quarantine, it is essential to stay active and maintain a physical exercise routine for mental and physical health. It is very important people should continue their active lives at home so that their lifestyles do not change and their health conditions do not deteriorate. The aim of the study is to determine the exercises that can be done during the COVID-19 outbreak and the points to be considered during the exercises.
\end{abstract}

Özet Çin'in Hubei Eyaleti, Vuhan Şehrinde, 31 Aralık 2019'da etiyolojisi bilinmeyen pnömoni vakaları ile gündeme gelen COVID-19 dünyaya yayılmaya başlamış ve buna bağlı ölümler hızla artmıştır. $\mathrm{Bu}$ hastalığın kontrolünde önemli basamak olan izolasyonun fizyolojik ve psikolojik birçok etkisi vardır. Ani bir karantina durumunun başlatılması, nüfusun yaşam tarzında radikal bir değişiklik anlamına gelmektedir. Değissen yaşam biçimleri ve davranışları, yetersiz fiziksel aktivite seviyesi ve yetersiz hareket ile sonuçlanabilir ve bu durum diyabet, hipertansiyon, kardiyovasküler hastalıklar, solunum yolu hastalıklar1 gibi durumların oluşma riskini artırır. Karantina sırasında, zihinsel ve fiziksel sağllk için aktif kalmak ve fiziksel bir egzersiz rutini korumak esastır. İnsanların yaşam tarzlarının değişmemesi ve sağlıklarının bozulmaması için evde aktif yaşama devam etmeleri çok önemlidir. Yapılan çalışmanın amacı, COVID-19 salgını esnasında yapilabilecek egzersizler ve egzersiz esnasinda dikkat edilmesi gereken hususların belirtilmesidir.

\footnotetext{
1 Makalede kullanılan veriler yayın tarihi itibariyle günceldir.

2 Doç. Dr. Niğde Ömer Halisdemir Üniversitesi, Spor Bilimleri Fakültesi, zaitburak@gmail.com (D) Orcid ID: 0000-0002-5102-4331

3 Prof. Dr. Niğde Ömer Halisdemir Üniversitesi, Spor Bilimleri Fakültesi, ruchaniri@ohu.edu.tr (D) Orcid ID: 0000-0002-6520-873X

${ }^{4}$ Doç. Dr. Selçuk Üniversitesi, Enfeksiyon Hastalıkları ve Klinik Mikrobiyoloji ABD, naktugdemir@yahoo.com (iD) Orcid ID: 0000-0002-4703-0827
} 
Keywords: Covid-19; Immune system; Anahtar Kelimeler: Covid-19; Bağışıklık Quarantine; Exercise. sistemi; Karantina; Egzersiz.

(Extended English summary is at the end of this document)

\section{Giriş}

\subsection{COVID-19’un Ortaya Çııışı, Yayılması ve Önlemler}

Koronavirüsler, tek zincirli, pozitif polariteli, zarflı RNA virüsleridir. İnsanlarda basit bir üst solunum yolu enfeksiyonundan, ağır akut solunum sendromuna kadar değişik tablolara neden olabilir. Koronavirüslerin insanlarda üst solunum yolu enfeksiyonuna neden olan alt tipleri $\mathrm{HCoV}$ 229E, HCoV-OC43, HCoV-NL63 ve HKU1-CoV olarak tanımlanmıştır (Perlman, 2020; Tang ve ark., 2020). Bununla birlikte hayvanlarda saptanan birçok koronavirüs alt türü mevcuttur ve bu virüslerin hayvanlardan insanlara geçerek insanlarda ağır hastalık tablolarına neden olabildiği bilinmektedir. 2002-2003 yllında ortaya çıkan SARS-CoV salgının misk kedilerinden, 2012 y1lında görülen MERS-CoV salgının ise tek hörgüçlü develerden insanlara bulaştığı ortaya çıkmıştır. 31 Aralık 2019'da Dünya Sağlık Örgütü (DSÖ) Çin Ülke Ofisi, Çin'in Hubei eyaletinin Vuhan şehrinde etiyolojisi bilinmeyen pnömoni vakalarını bildirmiştir. 7 Ocak 2020 'de bu vakalara neden olan etkenin daha önce insanlarda tespit edilmemiş yeni tip koronavirüs (2019- nCoV) olduğu belirlenmiştir. Daha sonra 2019-nCoV hastalığının adı COVID-19 olarak kabul edilmiss, virüs SARS-CoV'e yakın benzerliğinden dolayı SARS-CoV-2 olarak isimlendirilmiştir. Bu virüsün kaynağı net olarak bilinmemekle birlikte, Huanan deniz ürünleri toptan satış pazarında satılan vahşi hayvanlardan bulaştığı düşünülmektedir (World Health Organization, 2020). COVID-19 damlacık ve temas yoluyla bulaşmaktadır. Hasta bireylerin öksürme, hapşırma yoluyla ortaya saçtıkları damlacıklar temel bulaş yolu iken, bu damlacıklarla enfekte olmuş yüzeylerle temas sonrası ellerin temizlenmeden ağız, burun veya göz mukozasina temas etmesi diğer önemli bulaşma yoludur (Centers for Disease Control and Prevention, 2020). Enfeksiyonun yaygın belirtileri ateş, öksürük ve nefes darlı̆̆ıdır (Bajema ve ark., 2020; Huang ve ark., 2020).

Çin'in Hubei Eyaleti, Vuhan Şehrinde, 31 Aralı 2019'da etiyolojisi bilinmeyen pnömoni vakaları ile gündeme gelen COVID-19 hızla dünyaya yayılmaya başlamıștır. Mart 2020 başı itibariyle Çin'de salgının hızı yavaşlarken, İran, Kore Cumhuriyeti (Güney Kore) İtalya, İspanya, Amerika Birleşik Devletleri’nde COVID-19 vakaları ve buna bağlı ölümler hızla artmaktadır. 10 Mayıs 2020 tarihi itibarıyla Dünya'da 4.117.329 onaylanmış vaka, 1.446.713 iyileşen varken, virüs nedeniyle 280.697 hasta hayatını kaybetmiştir (Worldometer, 2020).

Şuan için bu hastalığın kontrol altına alınmasında en önemli şeyin enfekte bireylerin filiasyonunun yapılması ve izolasyonun sağlanması olduğu bilinmektedir. Bu nedenle Dünya Sağlık Örgütü COVID-19'u pandemi ilan etmiş ve ABD'de de ulusal acil durum ilan edilmiştir. İspanya ve İtalya'da tüm ülke karantina altına alınmış, Türkiye'nin de dahil olduğu dünyanın birçok ülkesinde geçici süreli dışarı çıkma yasakları uygulanmıştır (World Health Organization, 2020; Worldometer, 2020).

Bu hastalığın kontrolünde önemli basamak olan izolasyonun fizyolojik ve psikolojik birçok etkisi vardır (Karatosun, 2010; Şenışık, 2015). Ani bir karantina durumunun başlatılması, nüfusun yaşam tarzında radikal bir değişiklik anlamına gelmektedir. Değişen yaşam biçimleri ve davranışları, yetersiz fiziksel aktivite seviyesi ve yetersiz hareket ile sonuçlanabilir (Lavie ve ark., 2019; Ozemek ve ark., 2019). Bu durum diyabet, hipertansiyon, kardiyovasküler hastaliklar, solunum yolu hastalıkları gibi durumların oluşma riskini artırır (Fletcher ve ark., 2018; Ozemek ve ark., 2018). Bireylerin bu süreci sağlıklı atlatabilmeleri için bu hayata uyum sağlamaları çok önemlidir. Karantina sırasında, zihinsel ve fiziksel sağlık için aktif kalmak ve fiziksel bir egzersiz rutini korumak esastır (Karatosun, 2010; Şenışık, 2015). İnsanların yaşam tarzlarının değişmemesi ve sağlıklarının 
bozulmaması için evde aktif yaşama devam etmek çok önemlidir (Jiménez-Pavón ve ark., 2020). Fiziksel bir aktivite için açık hava insanlara daha uygun şartlar sunar ve daha çok tercih edilir. Fakat bu, karantina sırasında evde egzersiz yapılamayacağı anlamına gelmemektedir (Jiménez-Pavón ve ark., 2020). Çünkü evde yapılacak doğru egzersizler bağışıklı sistemimizi güçlendirebilir ve COVID-19 hastalı̆̆ının olumsuz etkilerini azaltmakta bize yardımcı olabilir. Egzersizin bağışıklık sistemi üzerindeki etkileri egzersizin yoğunluğu, süresi, şiddeti ve bireyin fiziksel uygunluk düzeyine göre değişkenlik gösterir (Şenışık, 2015).

\subsection{Egzersiz ve Bağışıklık Sistemi}

Hafif ve orta şiddette egzersiz bağışılklk sistemini olumlu yönde etkiler. Hafif ve orta şiddetteki egzersizden sonra natural killers $(\mathrm{NK})$ hücrelerinin etkinliği artar, nötrofil ve makrafoj fonksiyonları uyarılır, T ve B lenfosit hücre sayı ve etkinlikleri artar. Bu nedenle düzenli orta şiddette yapılan egzersiz üst solunum yolu hastalıklarına karşı direnci arttıırı (Şenışık, 2015; Nieman ve ark., 1994; Gleeson, 1985). Harris (2011) orta şiddetli egzersiz yapan kişilerde üst solunum yolu enfeksiyonu görülme olasılı̆̆ının \%20-30 oranında azaldığını bildirmiştir.

Uzun süreli yüksek şiddetli egzersizler ise immünosupresyona yol açar (Martin ve ark., 2009; Ahmadinejad ve ark., 2014). Yüksek şiddetli uzun süreli bir egzersizi takiben lenfosit konsantrasyonu düşer ve hücrelerin çoğalma yeteneği, orta düzeydeki sitotoksik aktivite ve immünoglobülin üretimi azalır, bunların sonucunda bağışıklık sistemi baskılanır (Şenışık, 2015; Nieman ve ark., 1994; Tvede ve ark., 1989). Bu tür egzersizleri izleyen birkaç saat boyunca bağışıklık sistemi zayıflar ve bu dönemde solunum yolu enfeksiyonu riski artar (Ahmadinejad ve ark., 2014).

Kısacası egzersiz ve bağışılklı sistemi arasında "J" formunda eğri modeli ile gösterilen bir ilişki tanımlanmıştır. Bu modele göre şiddetli egzersiz üst solunum yolu enfeksiyon riskini artırırken, orta şiddetteki egzersiz üst solunum yolu enfeksiyon riskini azaltmaktadır (Şenışı, 2015; Ahmadinejad ve ark., 2014; Tvede ve ark., 1989).

\subsection{COVID-19 ve Sağlıklı Yaşam için Egzersiz}

Fiziksel aktivite ve egzersiz sağlığ korumak, fiziksel uygunluğu geliştirmek ve performans1 artırmak olarak farklı amaçlar için yapılmakta ve amaçlanan durumu geliştirmek için farklı içeriklere sahip olmaktadır.

Sağllğı korumak ve fiziksel uygunluğu geliştirmek amacıyla COVID-19 salgını esnasında evde uygulanması gereken egzersizlerle ilgili yapılan bir çalısmada Jiménez-Pavón ve ark. (2020) yaşlı kişilere haftada en az 150-300 dakika aerobik egzersiz ve haftada 2 direnç antrenman seans1 önermektedir. Jiménez-Pavón ve ark. (2020) karantina altında, normal günlük fiziksel aktivite seviyelerindeki azalmayı telafi etmek için yapılan aktivitelerin 5-7 gün arasına dağıtılarak, haftada 200-400 dakikaya çıarılmasını tavsiye etmiştir. Ayrıca karantina zamanlarında yapılan bu aktivitelerin orta yoğunlukta (\% 40-60 kalp atım hız1 rezervi veya maksimum kalp atım hızının \% 65-75'i) olması gerektiğini rapor etmişlerdir. Evde yapılan bu egzersizlerde, kişilerin egzersizin uygulanması için gerekli özel materyalleri olmasa bile evde bulunan; bir sandalyeyi tutarak squat yapmak, sandalyeye oturup-kalkmak, bir yüksekliği basamak olarak kullanıp inip-çıkmak gibi aerobik egzersizleri, hafif ve orta ağırlıkta (sebze, pirinç, su, vb.) öğeleri taşımak gibi kuvvet egzersizleri, bir çizgide yürümek, ayak parmaklarında veya topuklarda yürümek gibi denge egzersizlerini yapılabileceğini söylemişlerdir. Halabchi ve ark. (2020) COVID-19 hastalığında egzersiz yapalım mı? Yapmayalım mı? sorusuna cevap aradığı çalışmasında orta yoğunluklu egzersizin asemptomatik sağlıklı kişiler için yararlı olabileceğini belirtmiş ve önermiştir. Bu egzersizlerin hastalı̆̆ın yüksek yayılma riski (kişiden kişiye veya kontamine yüzeyler) nedeniyle, özel ortamlarda (ev gibi) iyi havalandırma ve kişisel ekipman kullanımı ile uygun olabileceğini belirtmişlerdir. Halabchi ve ark. (2020) dişarı çıkma yasağı yok ise, çevredeki kişiler ile güvenli mesafeyi koruyarak diş ortamlarda, orta şiddetli aerobik egzersizin (tempolu yürüyüş gibi) uygun bir alternatif olabileceğini belirtmiş, kalabalık ortamlarda yapılan egzersizlerden ve yüksek şiddetli egzersizlerden ise uzak durulmasını önermişlerdir. Lippi ve ark. (2020) karantina altında fiziksel aktivite düzeyinin azalmasının diyabet 
(Bhaskarabhatla ve Birrer, 2005), kanser (Sanchis-Gomar ve ark., 2015), osteoporoz (Castrogiovanni ve ark., 2016) ve kardiyovasküler hastalık (Lippi ve Sanchis-Gomar, 2020) gibi risk faktörlerini artıracağını belirtmişlerdir. Bu nedenle, Lippi ve ark. (2020) dünya çapındaki ulusal, federal ve bölgesel hükümetleri, vatandaşlarını fiziksel aktiviteye teşvik etmeye davet etmiştir. Ayrıca Lippi ve ark. (2020) kişisel mesafelerin korunarak dış mekanlarda fiziksel aktivitenin güvenli bir şekilde gerçekleştirilmesine izin verilmesi gerektiğini, videolar ve online eğitimlerle kişilerin fiziksel aktiviteye teşvik edilmesini önermiştir. Zhu’nun (2020) Dr. Woods ile yaptığ1 soru cevap şeklindeki çalışmasında Dr. Woods alışılmamış yorucu veya uzun süreli egzersizin bağışıklık sistemi savunmalarımızın işlevini azaltabileceğini, bu nedenle, alısı1k olmadığınız uzun ve stresli egzersiz seanslarından kaçınmak gerektiğini belirtmiştir. Dr. Woods orta derece üst solunum yolu semptomları olan (burun akıntıs1, sinüs tıkanıklığı, hafif boğaz ağrısı) COVID-19 hastalarının orta şiddetli egzersiz yapabileceğini fakat şiddetli boğaz ağrıs1, vücut ağrıları, nefes darlığı, genel yorgunluk, göğüs öksürüğü ve ateş gibi semptomları olan hastaların egzersiz yapmamalarını ve tıbbi destek almaları gerektiğini söylemiştir.

Yukarıdaki çalışmalarda belirtildiği gibi orta şiddetli aerobik egzersizlerin bağışıklık sistemi direncini artırdığından dolayı COVID-19 hastalığına karşı bu tür egzersizlerin yapılması tavsiye edilebilir. Kissiler evde yaptıkları egzersizlerde, karantina öncesindeki egzersizle harcadıkları enerji miktarına ulaşabilir. Fakat karantina süreci öncesinde kişiler günlük işlerini yerine getirmek için karantina sürecinden daha fazla enerji harcamaktadır (işe yürüyerek gitmek, alış veriş yapmak, merdiven çıkmak gibi). Bu nedenle arada oluşacak aktivite eksikliğini kapatmak ve yaşam rutinini benzer şekilde devam ettirebilmek için egzersizin şiddeti ile oynamadan egzersizin süre ya da sıklı̆̆ının artırılması gerekmektedir. Diğer bir sorun kişilerin yaptıkları aktivitelerin süresi, şiddeti, sıklığ gibi konularda yeterli bilgiye sahip olmamasıdır. Birçok kişi internet üzerinden izledikleri videolara göre egzersiz yapmaktadır. Fakat bu videoların büyük bir kısmı kişilerin yaş, cinsiyet, fiziksel uygunluk durumlarını göz ardı ederek herkes için aynı egzersiz modellerini önermektedir. Bu eksikliğin giderilmesi için hükümetlerin vatandaşlarına yaş, cinsiyet ve fiziksel uygunluk düzeylerine göre egzersiz programları sunabilecekleri iletişim ağları kurmaları ve bu şekilde insanlara ulaşmaları gerektiğini düşünmekteyiz. Ayrıca evde geçirilen zamanın büyük bir kısmının hareketsiz TV veya bilgisayar başında geçirildiği düşünüldügünde, hükümetlerin TV’lerde inaktivitenin zararlarını açıklayan ve evde de egzersiz yapılabileceğini hatırlatan kamu spotlarını ara ara ekranlara getirmesini öneriyoruz. Örneğin, bir film ya da dizi yayındayken alttan geçen 'sağllk için harekete geçin' gibi vatandaşları bilinçlendirecek bilgilerin verilmesi.

\subsection{COVID-19 ve Performans Sporcularında Egzersiz}

$\mathrm{Bu}$ kısma kadar sağlık için egzersiz yapan ve fiziksel uygunluklarını korumaya çalışan kişilerden bahsettik. Fakat performans geliştirme amacıyla egzersiz yapan yarışmacı sporcular bu karantina süreçlerini nasıl geçirmeliler? COVID-19 hastalığının ilk başlangıçta, taraftarlar arasında yakın temas yoluyla iletimi azaltmak için müsabakaların seyirci olmadan devam edilmesi konusunda ortak bir görüşe varılmıştır. Fakat COVID-19 hastalığının çok hızlı bir şekilde yayılması ile tüm büyük spor ligleri ve turnuvaları, Mart 2020'nin başından itibaren askıya alınmıştır. Avrupa Futbol Federasyonları Birliği (UEFA) 2020 Avrupa Şampiyonasını bir yıl ertelemiş 11 Haziran 2021 yllında başlamasına karar vermiştir. Aynı şekilde Uluslararası Olimpiyat Komitesi (IOC) 2020 Tokyo Olimpiyat Oyunlarını bir yıl süre ile ertelemiştir. Bu esnada sporcuların korunması için takımlar antrenmanlarını iptal etmiş ve sporcular antrenmanlarına bireysel olarak devam etmek zorunda kalmıstır.

Antrenman şiddetlerinin bağışılılı sistemi üzerine etkileri düşünüldüğünde yarışmacı sporcuların formlarını korumak için gerekli olan yüksek şiddetli egzersizlere devam edip etmeyecekleri konusu ciddi bir sorun olarak ortaya çıkmıştır. Çünkü sporcular düşük şiddetli egzersizler ile form durumlarını koruyamazken, yüksek şiddetli egzersizler ile bağışıklık sistemlerini baskılayarak hastalığa yakalanma riskinde bir artış meydana getirebilir. Hull ve ark. (2020) elit sporcuların, hastalık semptomları bulunmuyorsa antrenman yükünde ani bir artış olmaması 
koşuluyla yüksek şiddetli antrenmana devam edebileceğini belirtmiştir. Başka bir öneri ise benzer hastalıklarla ilgili daha önceden yapılan çalışmalar düşünülerek COVID-19 riskini önlemek için sporcuların antrenman seansların $<60$ dakika ve maksimum şiddetin $<\%$ 80'ine kadar sınırlamaları şeklindedir (Campbell ve Turner, 2018). Brett ve ark. (2020) asemptomatik olmasına karşın seyahat yapan veya COVID-19 olan bir kişiyle yakin temas nedeniyle izole edilen sporcuların kardiyovasküler uygunluklarının korumasının zor olabileceğini belirtmiştir. Bu süre içerisinde sporcuların sabit bisiklet, koşu bandı ve direnç egzersizleri için gerekli ekipmanları varsa antrenmanlarına devam etmesini önermiş, bu antrenmanların uzaktan izleme ile antrenörler tarafından oluşturulması ve kontrol edilmesi gerektiğini belirtmiştir. Ayrıca Brett ve ark. (2020) COVID-19 olan sporcuların, semptomlar tamamen düzeldiğinde ve enerji seviyeleri normale döndüğünde egzersizlere başlayabileceğini ve semptomların giderilmesinden sonra en az 72 saat boyunca evde izolasyonun gerekli olduğu ve bu süre içerisinde evde düşük şiddetli egzersizler yapılabileceklerini söylemişlerdir.

Yarışmacı sporcuların performanslarını korumak için hem yüksek şiddetli egzersizlere ihtiyacı olduğu hem de yüksek şiddetli egzersizlerin bağışıklık sistemini baskıladığ1 düşünüldügünde, bu sporcuların izolasyonlarını çok iyi yapmaları şartı ile (başka insanlar ile temaslarını tamamen keserek) yüksek şiddetli egzersizlere devam etmesini önermekteyiz. Ayrıca evde yapılan egzersiz yüklerinin takımla yapılan egzersiz yüklerine ulaşmasının mümkün olmadığından sporcularda bir performans kaybı oluşacağı, bu nedenle karantina süreci sonrası liglerin yeniden açlmasından önce en az 3-4 haftalık bir hazırlık sürecinin takımlara verilmesi gerektiğini düşünmekteyiz.

\section{Sonuç ve Öneriler}

- Karantina altındaki kişilerin orta şiddetli egzersizler yapmasının hem fiziksel uygunluklarını korunmada hem de bağışıklık sistemini güçlendirmede önemli olduğunu,

- Karantina alındaki kişilerin normal yaşamlarındaki fiziksel uygunluklarını korumaları için haftada en az 4-5 gün (aerobik egzersizler, kuvvet egzersizleri) egzersiz yapmalarını,

- Dişarı çıkma yasağı olmayan yerlerde sosyal mesafenin korunarak (2 metre) açık havada egzersiz yapilabileceğini,

- Hükümetlerin vatandaşlarını egzersizin önemi hakkında bilinçlendirecek kamu spotları hazırlamalarını,

- Hükümetlerin vatandaşlarına yaş, cinsiyet ve fiziksel uygunluk düzeylerine göre doğru egzersiz programları sunabilecekleri iletişim ağları kurmalarını,

- Yarışmacı sporcuların performanslarını koruyabilmeleri açısından yüksek şiddetli egzersizlere devam etmelerini, fakat bu süreçte bağışıklık sisteminin zayıflayacağından dolayı izolasyonlarını doğru şekilde yapmalarını önermekteyiz.

\section{Kaynaklar}

Ahmadinejad, Z., Alijani, N., Mansori, S., Ziaee, V. (2014). Common sports related infections: a review on clinical pictures, management and time to return to sports. Asian J Sports Med, $5(1), 1-9$.

Bajema, K.L., Oster, A.M., McGovern, O.L., Lindstrom, S., Stenger, M.R., Anderson, T.C., Isenhour, C., Clarke, K.R., Evans, M.E., Chu, V.T., Biggs, H.M., Kirking, H.L., Gerber, S.I., Hall, A.J., Fry, A.M., \& Oliver, S.E. (2020). Persons evaluated for 2019 novel Coronavirus-United States, January 2020. MMWR Morb Mortal Wkly Rep, 69(6), 166170.

Bhaskarabhatla, K.V., \& Birrer, R. (2005). Physical activity and diabetes mellitus. Compr Ther, 31(4), 291-298.

Brett, G., Toresdahl, M.D., Irfan, M., \& Asif, M.D. (2020). Coronavirus disease 2019 (COVID-19): considerations for the competitive athlete. Sports Health, 12(3), 221-224. 
Campbell, J.P., \& Turner, J.E. (2018). Debunking the myth of exercise-induced immune suppression: redefining the impact of exercise on immunological health across the lifespan. Front Immunol, 9, 1-10.

Castrogiovanni, P., Trovato, F.M., Szychlinska, M.A., Nsir, H., Imbesi, R., \& Musumeci, G. (2016). The importance of physical activity in osteoporosis. From the molecular pathways to the clinical evidence. Histol Histopathol, 31(11), 1183-1194.

Centers for Disease Control and Prevention. (2020). Interim clinical guidance for management of patients with confirmed 2019 novel Coronavirus $(2019-\mathrm{nCoV})$ infection. https://www.cdc.gov/coronavirus/2019-ncov/hcp/clinical-guidance-management patients.html [Erişim tarihi: 05.05.2020].

Fletcher, G.F., Landolfo, C., Niebauer, J., Ozemek, C., Arena, R., \& Lavie, C.J. (2018). Promoting physical activity and exercise: JACC health promotion series. J Am Coll Cardiol, 72(14), 1622-1639.

Gleeson, M. (2007). Immune function in sport and exercise. J Appl Physiol, 103(2), 693-699.

Halabchi, F., Ahmadinejad, Z., \& Selk-Ghaffari, M. (2020). COVID-19 epidemic: exercise or not to exercise; that is the question! Asian J Sports Med, 11(1), e102630.

Harris, M.D. (2011). Infectious disease in athletes. Curr Sports Med Rep, 10(2), 84-89.

Huang, C., Wang, Y., Li, X., Ren, L., Zhao, J., Hu, Y., Zhang, L., Fan, G., Xu, J., Gu, X., Cheng, Z., Yu, T., Xia, J., Wei, Y., Wu, W., Xie, X., Yin, W., Li, H., Liu, M., Xiao, Y., Gao, H., Guo, L., Xie, J., Wang, G., Jiang, R., Gao, Z., Jin, Q., Wang, J., \& Cao, B. (2020). Clinical features of patients infected with 2019 novel coronavirus in Wuhan, China. Lancet, 395, 497-506.

Hull, J.H., Loosemore, M., \& Schwellnus, M. (2020). Respiratory health in athletes: facing the COVID-19 challenge. Lancet Respir Med, 8, S2213-2600(20)30175-2. [Epub ahead of print].

Karatosun, H. (2010). Fiziksel aktivite ve ruh sağllı̆ı. SDÜ Yaşam Dergisi, 2(2), 9-13.

Jiménez-Pavón, D., Carbonell-Baeza, A., \& Lavie, C.J. (2020). Physical exercise as therapy to fight against themental and physical consequences of COVID-19 quarantine: Special focus in older people. Prog Cardiovasc Dis, [Epub ahead of print].

Lavie, C.J., Ozemek, C., Carbone, S., Katzmarzyk, P.T., \& Blair, S.N. (2019). Sedentary behavior, exercise, and cardiovascular health. Circ Res, 124(5), 799-815.

Lippi, G., Henry, B.M., \& Sanchis-Gomar, F. (2020). Physical inactivity and cardiovascular disease at the time of coronavirus disease 2019 (COVID-19). Eur J Prev Cardiol, 9, 2047487320916823. [Epub ahead of print].

Lippi, G., \& Sanchis-Gomar, F. (2020). An estimation of the worldwide epidemiologic burden of physical inactivity- related ischemic heart disease. Cardiovasc Drugs Ther, 34(1), 133-137.

Martin, S.A., Pence, B.D., \& Woods, J.A. (2009). Exercise and respiratory tract viral infections. Exerc Sport Sci Rev, 37(4), 157-164.

Nieman, D.C., Miller, A.R., Henson, D.A., Warren, B.J., Gusewitch, G., Johnson, R.L., Davis, J.M., Butterworth, D.E., Herring, J.L., Nehlsen-Cannarella, S.L. (1994). Effect of high versus moderate exercise on lymphocyte subpopulations and proliferative response. Int J Sports Med, 15(4), 199-206.

Nieman, D.C. (1994). Exercise, infection, and immunity. Int J Sports Med, 15(3), 131-141.

Ozemek, C., Lavie, C.J., \& Rognmo, Ø. (2019). Global physical activity levels: need for intervention. Prog Cardiovasc Dis, 62(2), 102-107.

Ozemek, C., Laddu, D.R., Lavie, C.J., Claeys, H., Kaminsky, L.A., Ross, R., Wisloff, U., Arena, R., \& Blair, S.N. (2018). An update on the role of cardiorespiratory fitness, structured exercise and lifestyle physical activity in preventing cardiovascular disease and health risk. Prog Cardiovasc Dis, 61(5-6), 484-490.

Perlman, S. (2020). Another decade, another coronavirus. N EnglJ Med, 382, 760-762. 
Sanchis-Gomar, F., Lucia, A., Yvert, T., Ruiz-Casado, A., Pareja-Galeano, H., Santos-Lozano, A., Fiuza-Luces, C., Garatachea, N., Lippi, G., Bouchard, C., \& Berger N.A. (2015). Physical inactivity and low fitness deserve more attention to alter cancer risk and prognosis. Cancer Prev Res (Phila), 8(2), 105-110.

Şenışı, S.Ç. (2015). Egzersiz ve bağışıklık sistemi. Turk J Sports Med, 50, 11-20.

Tang, X., Wu, C., Li, X., Song, Y., Yao, X., Wu, X., Duan, Y., Zhang, H., Wang, Y., Qian, Z., Cui, J., \& Lu, J. (2020). On the origin and continuing evolution of SARS-CoV-2. National Science Review, nwaa036.

Tvede, N., Heilmann, C., Halkjaer-Kristensen, J., Pedersen, B.K. (1989). Mechanisms of Blymphocyte supression induced by acute physical exercise. J Clin Lab Immunol, 30(4), 169173.

World Health Organization. (2020). Novel Coronavirus (2019-nCoV) technical guidance. https://www.who.int/emergencies/diseases/novel-coronavirus-2019/technical-guidance [Erişim tarihi: 05.05.2020].

Worldometer. (2020). https://www.worldometers.info/coronavirus/ [Erişim tarihi:10.05.2020].

Zhu, W. (2020). Should, and how can, exercise be done during a coronavirus outbreak? An interview with Dr. Jeffrey A. Woods. J Sport Health Sci, 9(2), 105-107.

\section{Extended English Summary}

On December 31, 2019, China Country Office of the World Health Organization (WHO) reported pneumonia cases of unknown etiology in Wuhan in China's Hubei province. On 7 January 2020, it was determined that the cause of these cases was a new coronavirus (2019- nCoV), which had not been detected in humans before. Later, the name of the $2019-\mathrm{nCoV}$ disease was accepted as COVID-19 and the virus was named as SARS-CoV-2 because of its close resemblance to SARS $\mathrm{CoV}$. The origin of this virus is not known clearly but is thought to have been transmitted from wild animals sold in the Huanan seafood wholesale market (World Health Organization, 2020).

For now, it is known that the most important thing in controlling this disease is the infiltration and isolation of infected individuals.

Isolation, which is an important step in the control of this disease, has many physiological and psychological effects (Karatosun, 2010; Şenış1k, 2015). Initiating a sudden quarantine situation means a radical change in the lifestyle of the population. Changing lifestyles and behaviours may result in insufficient levels of physical activity and inadequate movement (Lavie et al., 2019; Ozemek et al., 2019), which increases the risk of developing conditions such as diabetes, hypertension, cardiovascular diseases and respiratory diseases (Fletcher et al., 2018; Ozemek et al., 2018). It is very important for individuals to adapt to this new lifestyle in order to survive this process healthily. During quarantine, it is essential to stay active and maintain a physical exercise routine for mental and physical health (Karatosun, 2010; Şenıssık, 2015). People should maintain active life at home so that their lifestyles do not change and their health does not deteriorate (Jiménez-Pavón et al., 2020). Open-air offers more favourable conditions to people and is more preferred for physical activity. However, this does not necessarily mean that exercise cannot be done at home during quarantine (Jiménez-Pavón et al., 2020). Because proper exercises at home can strengthen our immune system and help us reduce the negative effects of COVID-19 disease. The effects of exercise on the immune system vary depending on the intensity, duration, severity, and physical fitness level of the individual (Şenış1k, 2015).

A relationship represented by the curve model in the " $\mathrm{J}$ " form has been defined between exercise and the immune system. According to this model, while severe exercise increases the risk of upper respiratory tract infection, moderate exercise decreases the risk of upper respiratory tract infection (Şenış1k, 2015; Ahmadinejad et al., 2014; Tvede et al., 1989). 
In their study on home exercises that must be done to protect health and improve physical fitness during the COVID-19 outbreak, Jiménez-Pavón et al (2020) recommended that at least 150 to 300 minutes of aerobic exercise and 2 resistance training sessions per week should be practiced by the old. It was recommended by Jiménez-Pavón et al that, the activities carried out to compensate for the decrease in normal daily physical activity levels under quarantine should be increased to 200-400 minutes per week and distributed within 5-7 days. Shalabchi et al (2020) sought an answer to the question "Should we exercise in COVID-19 disease or not?" in their study and found that moderate-intensity exercise may be beneficial for asymptomatic healthy people. Halabchi et al (2020) stated that it may be a suitable alternative to moderate-intensive aerobic exercises (such as brisk walking) in outdoor environments maintaining a safe distance with the people around if there is no order of a curfew, but suggested avoiding exercises in crowded environments and high-intensity exercises. Lippi et al (2020) stated that reduced levels of physical activity under quarantine would increase the risk factors such as diabetes (Bhaskarabhatla and Birrer, 2005), cancer (Sanchis-Gomar et al., 2015), osteoporosis (Castrogiovanni et al., 2016) and cardiovascular disease (Lippi and Sanchis-Gomar, 2020). Therefore, Lippi et al (2020) invited national, federal, and regional governments worldwide to encourage their citizens to engage in physical activity.

So far, we talked about people who exercise for health and try to maintain their physical fitness. But how should contestant athletes who exercise for performance improvement go through these quarantine processes?

Considering the effects of training intensities on the immune system, the issue of whether or not competitive athletes should exercise the high-intensity exercises necessary to maintain their fitness has emerged as a serious problem. Because athletes cannot maintain their fitness with lowintensity exercises while high-intensity exercises can suppress the immune system and create an increased risk of developing the disease. Hull et al (2020) stated that, if the symptoms of the disease do not exist, elite athletes can continue high-intensity training provided that there is no sudden increase in training load. Brett et al (2020) stated that for athletes who are isolated due to close contact with a person traveling despite being asymptomatic or infected with COVID-19 it might be difficult to maintain cardiovascular fitness. The researchers suggested that the athletes continue their training if they have the equipment required for stationary bicycles, treadmills, and resistance exercises, and stated that these training programs should be prepared and controlled by the coaches with remote monitoring during this period.

As a result, it is recommended that;

- People under quarantine should do moderate-intensity exercises both to maintaining their physical fitness and to strengthen their immune system,

- People under quarantine should do physical activity (aerobic exercises, strength exercises) at least 4-5 days a week to keep their physical fitness in their normal lives,

- Exercise should be done outdoors by maintaining the social distance ( 2 meters) in places where there is no prohibition of going out,

- Governments should prepare public spots to raise awareness of citizens about the importance of physical activity,

- Governments should establish communication networks through which they can offer their citizens the right exercise programs according to their age, gender, and physical fitness levels,

- Contestant athletes should keep performing high-intensity exercises in order to maintain their performance but isolate themselves correctly since the immune system will weaken during this process. 